\title{
Geographical Analysis of Community Resilience to Seismic Hazard in Southwest China
}

\author{
Xiaolu $\mathrm{Li}^{1} \cdot$ Lei Wang ${ }^{2} \cdot$ Shan Liu ${ }^{1}$
}

Published online: 8 July 2016

(c) The Author(s) 2016. This article is published with open access at Springerlink.com

\begin{abstract}
This article presents an explorative analysis of community resilience to seismic hazard in the 2008 Wenchuan Earthquake area of Southwest China. We used a regression model to analyze the impact of 13 key socioeconomic and demographic variables on community resilience in 105 counties, based on data derived from population census and provincial statistical yearbooks of China. In this research, we argue that community resilience should be measured by the change of population growth rate $(\Delta d p)$ instead of population growth rate $(d p)$ when using socioeconomic data from a fast-growing country such as China. Using $\Delta d p$ as the dependent variable resulted in a better regression model. To avoid the common multicollinearity problems among the independent variables, a principal component-based factor analysis was used to consolidate the socioeconomic variables into four comprehensive factors. The geographically weighted regression coefficient maps revealed the spatial pattern of the association of the variables with resilience. We also used the K-means cluster method to segment the study area into four subregions that exhibit localized characteristics defined by the regression coefficients. In this way, we could infer location-sensitive disaster management policies that help to enhance social resilience to seismic hazards.
\end{abstract}

Lei Wang

leiwang@1su.edu

1 School of Automation, University of Electronic Science and Technology of China, Chengdu 611731, Sichuan, China

2 Department of Geography and Anthropology, Louisiana State University, Baton Rouge, LA 70810, USA
Keywords China $\cdot$ Community resilience $\cdot$ Geographic information system $\cdot$ Geographically weighted regression - Wenchuan Earthquake

\section{Introduction}

In a rapidly developing country like China, society becomes more vulnerable to seismic hazards because of the relatively low preparedness for disasters in comparison with the high speed growth of economy and population accompanied by fast urban expansion (Zheng et al. 2015). The 2008 Wenchuan Earthquake in Southwest China has attracted significant attention because it caused great casualties and substantial property losses ( $\mathrm{Li}$ et al. 2015a). Faced with potential future tragic losses from seismic disasters, China needs to address scientific questions such as: (1) Will severe losses slow down the recovery of the affected communities? (2) If not, what are the social and economic characteristics that would contribute most to post-disaster recovery and enhance the impacted community's resilience? (3) How should the government develop locally adapted strategic plans for optimized regional recovery with limited resources?

The definition of social resilience has been discussed in the literature (Holling 1973, 1996; Adger et al. 2005; Cutter et al. 2008). Turner et al. (2003) have pointed out that vulnerability is not only just exposure to hazards, but also includes sensitivity and resilience to disastrous events. Some researchers (such as Norris et al. 2008) have suggested that resilience can be understood as a "capacity," a "process," an "outcome," or a certain combination of these three concepts for reducing damage and improving recovery. Brown and Kulig (1996) used community resilience to measure different communities' recoverability or adjustability from misfortune. Paton and 
Johnston (2001) defined community resilience as the capacity to recover from hazard damage and the ability to effectively deal with future exposure to hazards. We adopt the definition of resilience proposed by the United States National Research Council (NRC 2012, p. 1), which considers resilience to be "...the ability to prepare and plan for, absorb, recover from, and more successfully adapt to adverse events over time." Through an explorative analysis using regression models, this research identifies the economic and social characteristics of disaster-stricken communities that could affect their postdisaster recovery. We anticipate that the scientific findings from this research can help government agencies and policymakers formulate quick response strategies to seismic disasters so a disaster area can quickly return to its normal status, or in other words, achieve greater resiliency.

Previous research has suggested that a variety of statistical models can successfully evaluate the association of resilience and socioeconomic variables. For example, Cutter et al. (2008) provided a theoretical framework for local scale resilience assessment-the disaster resilience of place model. These authors treated resilience as a continuous dynamic process influenced by both exposure and exogenous factors from social systems. Later Cutter et al. (2010) introduced another set of indicators to derive a baseline resilience index for communities. Lam et al. (2015) used the resilience inference model to assess community resilience to hurricane hazards. Bruneau et al. (2003) developed a quantitative framework that measured the speed of recovery using four resilience dimensions (technical, organizational, social, and economic) of four systems (electric power, water, hospital, and local response and recovery systems). Based on this framework, they evaluated how economic losses would affect resilience.

Many social science researchers have criticized quantitative methods because numeric measures often neglect the uniqueness of a society or its individual members. Such uniqueness requires that the policies inferred from simulation models must be location sensitive (Cloke et al. 1991; Smith 1998). In most applications of geographical analyses, statistical approaches are used in a "cookbook" fashion without considering the spatial features of the data (Fotheringham et al. 2000). General nonspatial statistical models do not incorporate locational information in their calculations, and therefore they are not suitable for policy making under conditions of geographical heterogeneity (Zheng et al. 2016). Although the important role of geographic information systems (GIS) in disaster management sciences is widely accepted, most research has only used GIS as a mapping and data collection tool (Zheng et al. 2013), and has neglected the ability of GIS to provide spatially varied disaster mitigation plans and recovery strategies. In this research, we have introduced a geographically weighted regression (GWR) model supported by a GIS in order to build location-dependent regression models. The aim is to find a better strategic approach to community recovery and sustainable socioeconomic development in earthquake disaster areas. GWR is a local regression model that could reconcile the use of statistical regression models with GIS (Fotheringham et al. 1998, 2003). The use of locally sampled data and distanceweighted solutions addresses the spatial nonstationarity problem of regression models. In addition, the regression coefficients from GWR exhibit a certain spatial pattern, the correct reading of which could help better understand the association of resilience with socioeconomic variables place by place (Brunsdon et al. 1998). We can derive location-specific disaster management plans that effectively assist to enhance the sustainability of those areas that are threatened by seismic hazards.

\section{Study Area and Data Sources}

The study area is the region in southwestern China that was impacted by the Wenchuan Earthquake in 2008, including the epicenter and surrounding areas in Sichuan Province (Fig. 1a). The Wenchuan Earthquake caused over 69,227 casualties and resulted in losses of RMB 845.1 billion Yuan (over USD 130 billion); more than $90 \%$ of these losses occurred in Sichuan Province (Guo 2012). The quake intensity map in Fig. $1 \mathrm{~b}$ was based on the data provided by the United States Geological Survey (USGS 2008). As shown in Fig. 1b, the earthquake intensity peaked at the epicenter in Wenchuan and Lixian Counties, and gradually weaker impacts occurred up to about $200 \mathrm{~km}$ away. Figure 1c shows the area with major damage and losses caused by the earthquake, measured in loss per capita derived from the 2008 Sichuan Statistical Yearbook (Sichuan Provincial Bureau of Statistics 2008).

Demographic and socioeconomic data used in the study were selected from the 2000 population census of the People's Republic of China (National Bureau of Statistics of the People's Republic of China 2001) and the Sichuan Statistical Yearbooks of 2003 and 2008 (Sichuan Provincial Bureau of Statistics 2003, 2008). Many indicators for the measurement of community resilience are found in the disaster risk literature. Paton et al. (2000, 2006) found that the demographic characteristics of the community, including age, race, gender, occupation, and socioeconomic condition, were related to social resilience. Cutter et al. (2008) assessed community resilience according to economic indicators and community competence, such as employment, value of property, wealth generation, health and wellness, and so on. The H. John Heinz III Center for Science, Economics, and the Environment (2000) concluded that social vulnerability and resilience were 
Fig. 1 a The study area and the selected counties with data available, $\mathbf{b}$ intensity of the 2008 Wenchuan Earthquake interpolated from USGS earthquake dataset, $\mathbf{c}$ economic losses per capita of the counties, and $\mathbf{d}$ change of population growth rate of the counties $(\Delta d p)$ (a)

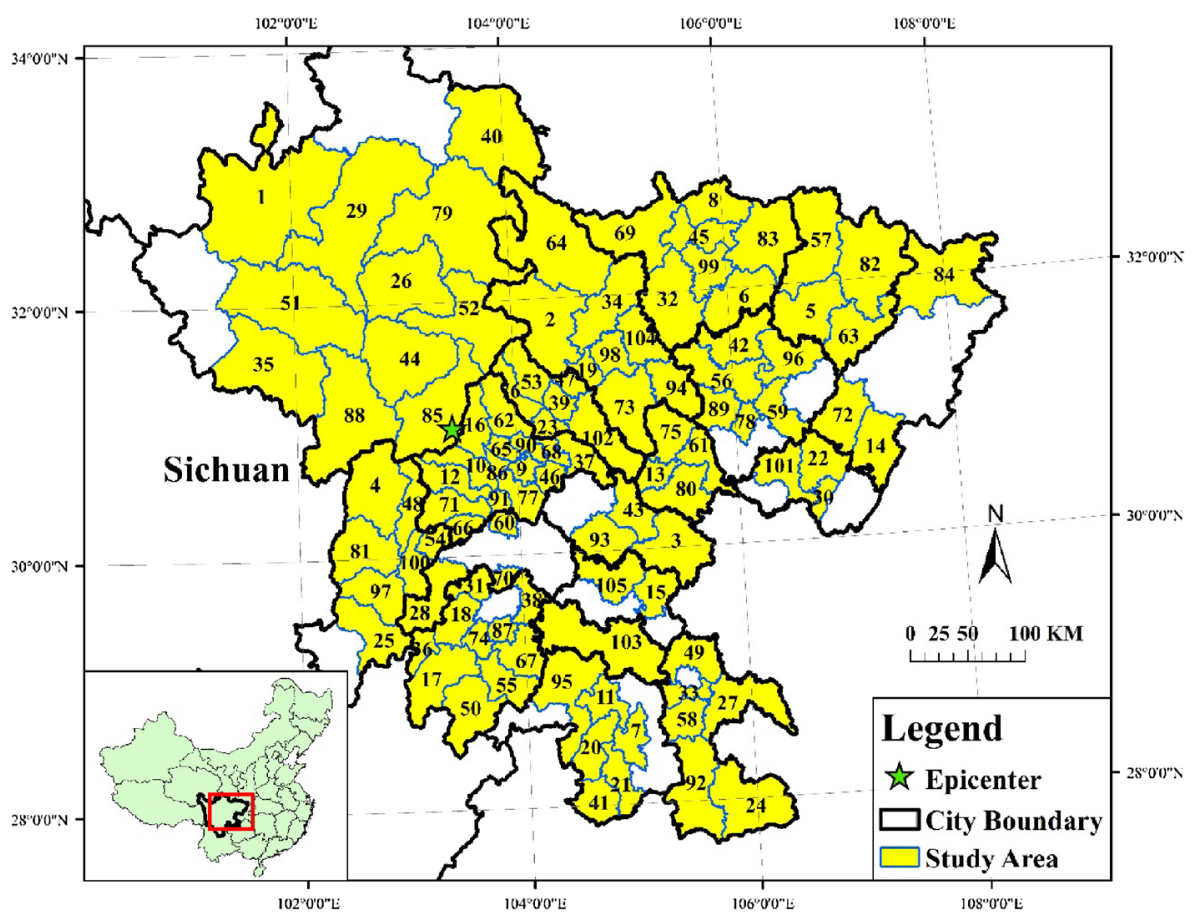

\begin{tabular}{|l|l|l|l|l|l|l|l|l|l|}
\hline 1 & Aba & 20 & Gaoxian & 42 & Langzhong & 64 & Pingwu & 85 & Wenchuan \\
\hline 2 & Anxian \& & 21 & Gongxian & 43 & Lezhi & 65 & Pixian & 86 & Wenjiang \\
\cline { 2 - 7 } & Beichuan & 22 & Guanganqu & 44 & Lixian & 66 & Pujiang & 87 & Wutongqiao \\
\hline 3 & Anyue & 23 & Guanghan & 45 & Lizhou & 67 & Qianwei & 88 & Xiaojin \\
\hline 4 & Baoxing & 24 & Gulin & 46 & Longquanyi & 68 & Qingbaijiang & 89 & Xichong \\
\hline 5 & Bazhou & 25 & Hanyuan & 47 & Luojiang & 69 & Qingchuan & 90 & Xindu \\
\hline 6 & Cangxi & 26 & Heishui & 48 & Lushan & 70 & Qingshen & 91 & Xinjin \\
\hline 7 & Changning & 27 & Hejiang & 49 & Luxian & 71 & Qionglai & 92 & Xuyong \\
\hline 8 & Chaotian & 28 & Hongya & 50 & Mabian & 72 & Quxian & 93 & Yanjiang \\
\hline 9 & Chengdu & 29 & Hongyuan & 51 & Maerkang & 73 & Santai & 94 & Yanting \\
\cline { 2 - 7 } & Metropolitan & 30 & Huaying & 52 & Maoxian & 74 & Shawan & 95 & Yibin \\
\cline { 2 - 6 } & Area & 31 & Jiajiang & 53 & Mianzhu & 75 & Shehong & 96 & Yilong \\
\hline 10 & Chongzhou & 32 & Jiange & 54 & Mingshan & 76 & Shifang & 97 & Yingjing \\
\hline 11 & Cuiping & 33 & Jiangyang & 55 & Muchuan & 77 & Shuangliu & 98 & Youxian \\
\hline 12 & Dayi & 34 & Jiangyou & 56 & Nanbu & 78 & Shunqing & 99 & Yuanba \\
\hline 13 & Daying & 35 & Jinchuan & 57 & Nanjiang & 79 & Songpan & 100 & Yucheng \\
\hline 14 & Dazhu & 36 & Jinkouhe & 58 & Naxi & 80 & Suining & 101 & Yuechi \\
\hline 15 & Dongxing & 37 & Jintang & 59 & Pengan & & Urban Area & 102 & Zhongjiang \\
\hline 16 & Dujiangyan & 38 & Jinyan & 60 & Pengshan & 81 & Tianquan & 103 & Zigong \\
\hline 17 & Ebian & 39 & Jinyang & 61 & Pengxi & 82 & Tongjiang & 104 & Zitong \\
\hline 18 & Emeishan & 40 & Jiuzhaigou & 62 & Pengzhou & 83 & Wangcang & 105 & Zizhong \\
\hline 19 & Fucheng & 41 & Junlian & 63 & Pingchang & 84 & Wanyuan & & \\
\hline & & & & & & \\
\hline
\end{tabular}

influenced by several socioeconomic characteristics including commercial and industrial development, residential property, level of education, and medical services, among others. But there has not been a consensus on the best core variables with which to study community resilience.

In light of previous vulnerability and resilience research (The H. John Heinz III Center for Science, Economics, and the Environment 2000; Paton et al. 2000; Cutter et al. 2003; Paton and Johnston 2006; Nelson et al. 2009), and considering the limited data availability in China, we selected
13 social and economic variables for our regression analysis, as listed in Table 1. Social condition was accounted for using total population, ethnic and urban populations, age, education levels, and employment variables. To account for the level of economic development, GDP per capita, proportion of primary industry, and proportion of secondary industry were selected to reflect economic influences on resilience. Additionally, we used average wage, per capita saving deposit balances, and the number of hospital and social welfare beds as the index of the level of living standard, medical treatment, and social welfare 
Fig. 1 continued
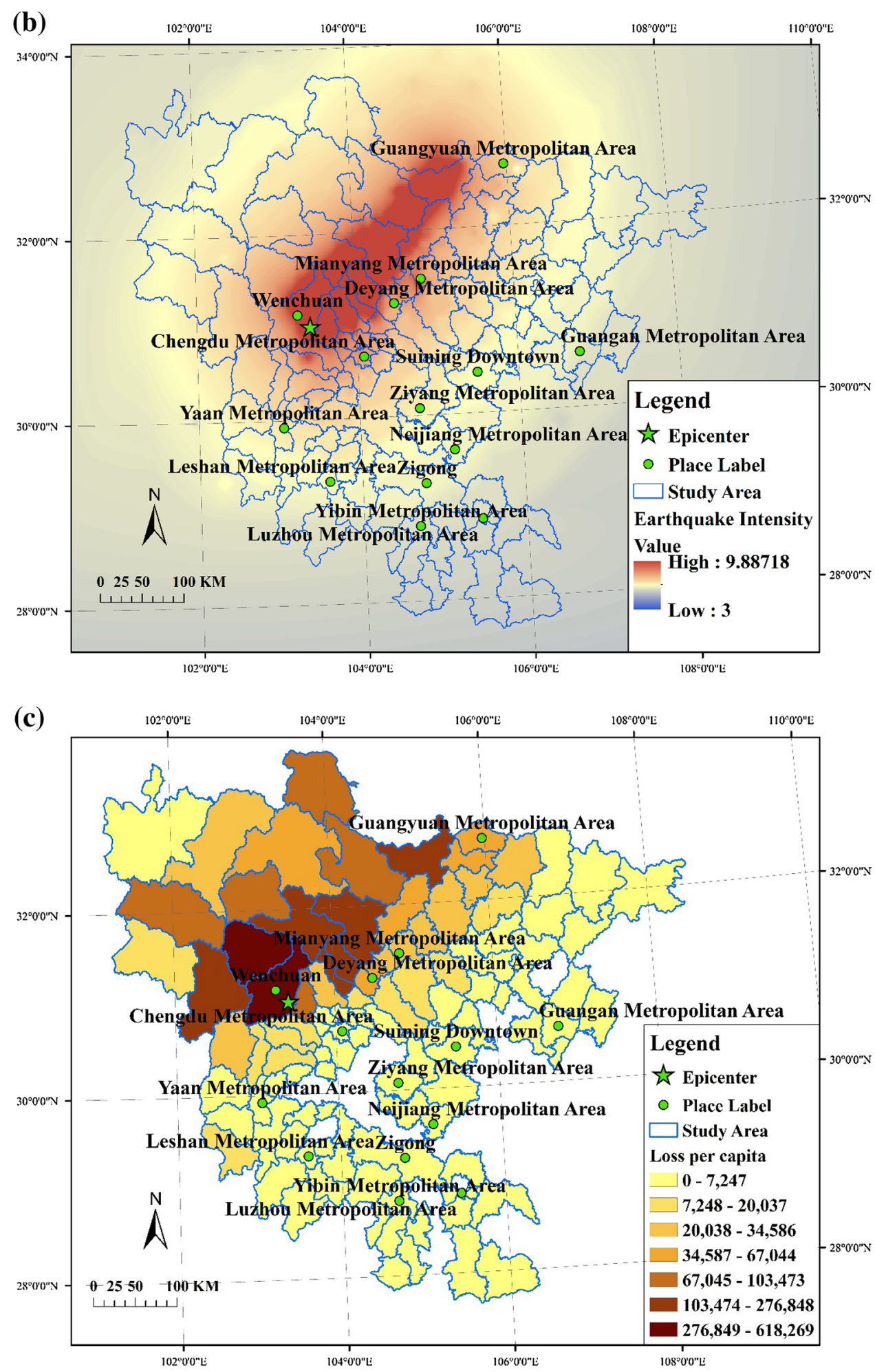

for each county. We opted to normalize the data by total population to avoid the modifiable areal unit problem (Fotheringham et al. 1995). Besides the variables in
Table 1, the total population data of 2005, 2007, 2008, and 2010 for each county were collected from the annual Sichuan Statistical Yearbooks (Sichuan Provincial Bureau 
Fig. 1 continued

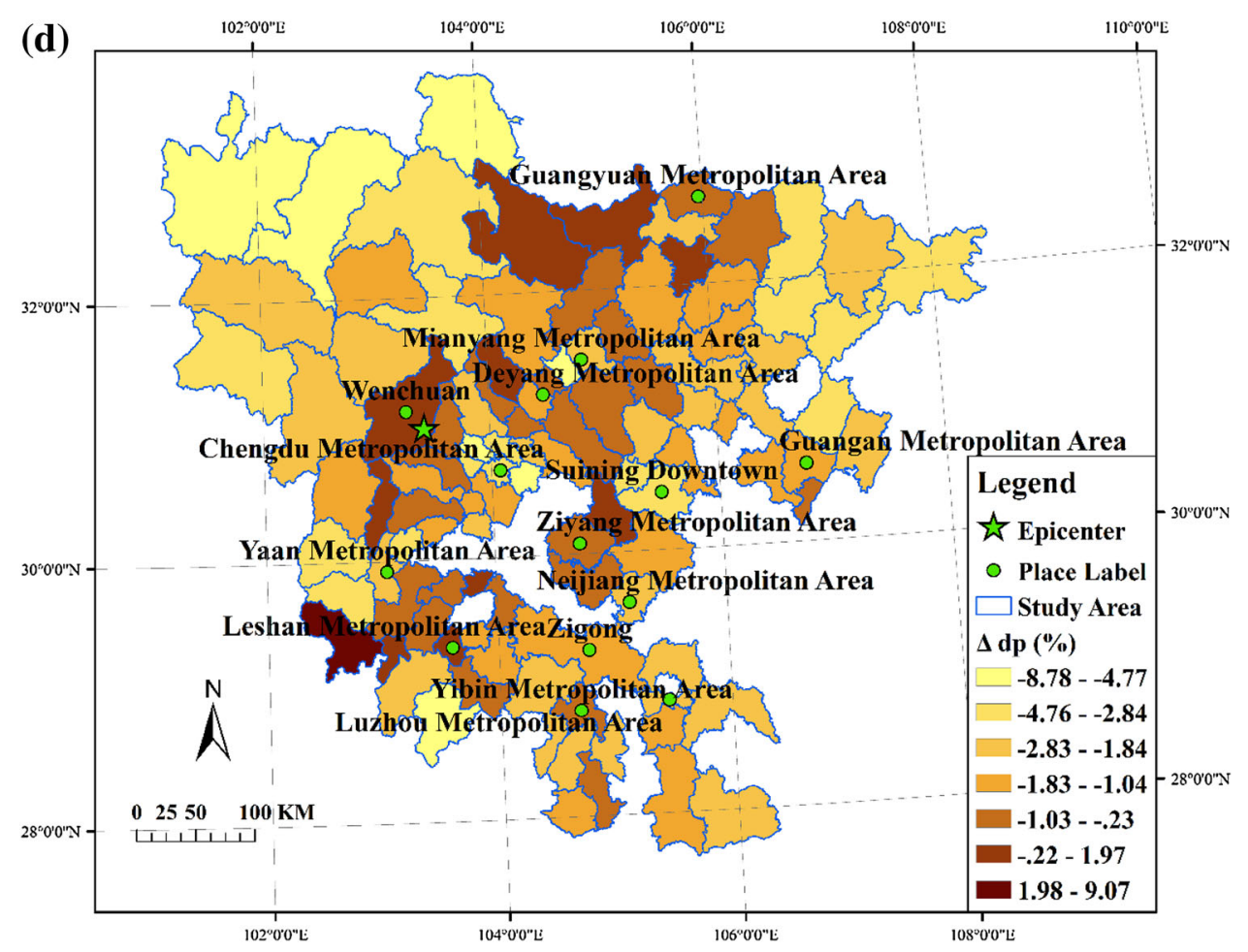

of Statistics 2006, 2008, 2009, 2011) to calculate the change of population growth rate $(\Delta d p)$ before and after the earthquake (Fig. 1d). Not all counties within the earthquake area were included in the analysis because of the missing data problem. For this reason, we merged five counties (Jinjiang, Jinniu, Qingyang, Wuhou, and Chenghua) into one unit of analysis as the Chengdu Metropolitan Area. We used the aggregated data of the Suining urban areas, instead of its two subareas: Chuanshan and Anju Counties. Furthermore, six counties of Zigong City experienced administrative boundary change between 2000 and 2010. Hence we used Zigong City as one study unit. For the same reason, we treated Beichuan and Anxian Counties as one unit. To ensure that the study area is contiguous, a few geographically isolated counties were not included, such as Kaijiang and Tongchuan Counties. As a result, a total of 105 units (Fig. 1a) from Sichuan Province were used for data analyses.

\section{Data Analyses}

In this section, we present the data analysis of the socioeconomic variables. First, we calculated the change in population growth rate $(\Delta d p)$ as the dependent variable. Then, we used the factor analysis to consolidate the explanatory variables into four factors. A global ordinary least squares (OLS) regression model was used to confirm the association between the dependent variables and the explanatory variables. The following GWR revealed the spatial dependence of the regression coefficients. We also carried out a K-means clustering analysis on the GWR coefficients to derive location-sensitive policies that would, if employed, enhance community resilience.

\subsection{Resilience Index}

In the hazard risk research literature, no consensus exists on what is the best way is to measure resilience (Bevington et al. 2011). Some scholars advocate the use of evacuation/ return ratio as a resilience measurement. However, the data for tracking population migration are not often available, especially for large study area like the one examined in this research. Even in a data-rich area such as New Orleans in the US after Hurricane Katrina in 2005, it is still impossible to track people's migration. Therefore, we chose to use the change in population growth rate $(\Delta d p)$ before and after the earthquake as the resilience index in this study. Population is a more summative variable to measure resilience than economic variables, such as GDP and income growth (Pelling 2003; UNISDR 2004; Cutter et al. 2008). Population growth $(d p)$ has been similarly used by many studies as the recovery indicator (Chang 2010; Finch et al. 2010; Li et al. 2010, 2015a). Nevertheless, this measure of population growth may include the portion from natural growth, which might have a higher contribution than the impact of disasters, especially in areas experiencing rapid urban expansion. For this reason, we used the measure of 
Table 1 Variables used in the study

\begin{tabular}{|c|c|c|c|c|c|}
\hline No. & Labels & Socioeconomic variables & Variable meaning & Units & Sources \\
\hline \multicolumn{6}{|c|}{ Demographic } \\
\hline 1 & PopDensity & Population density, 2007 & Population & Persons $/ \mathrm{km}^{2}$ & YB \\
\hline 2 & RtoEthPop & $\begin{array}{l}\text { Percentage of ethnic minorities } \\
\text { population, } 2000\end{array}$ & Ethnicity & $\%$ & $\mathrm{CS}$ \\
\hline 3 & RtoUrbanPop & Percentage of urban population, 2007 & Urban & $\%$ & YB \\
\hline 4 & RtoPopAge $15-64$ & $\begin{array}{l}\text { Percentage of population aged } 15-64, \\
2000\end{array}$ & Age & $\%$ & $\mathrm{CS}$ \\
\hline \multicolumn{6}{|c|}{ Social } \\
\hline 5 & RtoEduSec & $\begin{array}{l}\text { Percentage of population with education } \\
\text { of senior secondary school and } \\
\text { technical secondary school and above, } \\
2000\end{array}$ & Education & $\%$ & CS \\
\hline 6 & RtoEmpPop & Ratio of employed population, 2007 & Employment & $\%$ & YB \\
\hline \multicolumn{6}{|c|}{ Economic } \\
\hline 7 & GDPperCapita & GDP per capita, 2007 (at current price) & Commercial and industrial development & Yuan/person & YB \\
\hline 8 & PPriIndus & Proportion of primary industry, 2007 & Commercial and industrial development & $\%$ & YB \\
\hline 9 & PSecIndus & Proportion of secondary industry, 2007 & Commercial and industrial development & $\%$ & YB \\
\hline 10 & AvWages & Average wages of staff and workers, 2007 & Residential property & Yuan/person & YB \\
\hline 11 & PCSvgsDpstB & $\begin{array}{l}\text { Per capita savings deposit balances of } \\
\text { residents, } 2002\end{array}$ & Residential property & Yuan/person & YB \\
\hline \multicolumn{6}{|c|}{ Health } \\
\hline 12 & PCHospBed & $\begin{array}{l}\text { Number of hospital beds per } 10,000 \\
\text { persons, } 2007\end{array}$ & Medical capacity & Unit/10,000 person & YB \\
\hline \multicolumn{6}{|c|}{ Social welfare } \\
\hline 13 & PCSWBed & $\begin{array}{l}\text { Number of social welfare home beds per } \\
10,000 \text { persons, } 2007\end{array}$ & Social welfare & Unit/10,000 person & YB \\
\hline
\end{tabular}

The 2000 population census data were obtained from the National Bureau of Statistics of the People's Republic of China (CS) and the provincial statistical yearbooks 2003 and 2008 (YB)

change in population growth rate between the pre- and post-seismic event periods as the resilience index, which is calculated as:

$\Delta d p=\frac{P 2010-P 2008}{P 2008}-\frac{P 2007-P 2005}{P 2005}$,

where $\Delta d p$ is the difference of population growth rate before and after the 2008 Wenchuan Earthquake event, P2010 is the population of 2010, and so on. Figure 1d shows the spatial pattern of the change of population growth rate $(\Delta d p)$. We assume that the population growth rate was mainly affected by the earthquake disaster, that is, deaths, migration, and immigration. We make this assumption based on the following reasoning: (1) population growth rate is relatively stable in China unless there is an abrupt change in policies, such as birth control or fertility, (2) if the first assumption holds true, the change in population growth rate of the area during the 2005-2010 period should be associated with the major disaster event of 2008, and (3) communities with high resilience should maintain a relatively stable population growth rate when hit by such disasters.

\subsection{Factor Analysis}

For independent variables we use 13 socioeconomic variables. The descriptive statistics of these socioeconomic variables are shown in Table 2. Because the socioeconomic variables are always correlated, they must be selected or transformed to avoid the multicollinearity problem (Ghosh and Manson 2008). In this research, we employed principal component-based factor analysis to create a set of new variables that are orthogonal to each other. Factor analysis can reduce the dimensionality of the data by aggregating them to fewer comprehensive factors, reduce the possibility of multicollinearity existing in the variables, and at the same time maintain sufficient data variance with more comprehensive factors (Harman 1976; Chatfield and Collins 1980; Hair et al. 1998). Therefore, factor analysis is quite often used on multivariate data for dimension reduction or to condense multiple input variables to several orthogonal and meaningful factors (Hair et al. 1998). It is widely used for dealing with a large number of input variables that are potentially correlated to each other at a certain level. For example, many social studies have used 
Table 2 Descriptive statistics of socioeconomic variables for the study

\begin{tabular}{lrrrr}
\hline & Minimum & Maximum & Mean & Standard deviation \\
\hline PopDensity & 4.88 & 6542.92 & 510.83 & 676.38 \\
RtoEthPop & 0.02 & 94.11 & 9.58 & 23.72 \\
PtoPopAge15-64 & 61.75 & 80.28 & 70.11 & 3.51 \\
PtoEduSec & 3.89 & 40.98 & 9.66 & 5.51 \\
RtoUrbanPop & 5.77 & 100.00 & 23.74 & 15.02 \\
RtoEmpPop & 26.24 & 129.68 & 57.43 & 11.13 \\
PPriIndus & 0.17 & 52.12 & 25.78 & 12.37 \\
PSecIndus & 13.38 & 82.86 & 43.29 & 14.51 \\
GDPperCapita & 4645.00 & $50,246.49$ & $12,927.76$ & $79,647.42$ \\
AvWages & $12,997.00$ & $31,207.00$ & 3352.90 & 4448.45 \\
PCSvgsDpstB & 765.05 & $21,981.52$ & 24.27 & 2723.11 \\
PCHospBed & 0 & 71.23 & 13.84 & 8.84 \\
PCSWBed & 0 & 52.24 & & \\
\hline
\end{tabular}

factor analysis to derive a social vulnerability index (Cutter et al. 2003) for disaster science and management. Unlike the piecewise regression method that discards some input variables, factor analysis tends to retain useful information as much as possible from all variables. It also helps remove data noise by extracting a few principal components as factors, neglecting those components with low eigenvalues, which are possible noise components.

We conducted the factor analysis in the form of a principal component analysis (PCA) (Jolliffe 2010). Thirteen socioeconomic variables were put into the factor analysis module in the SPSS statistical software package. The variables were standardized to zero mean and unit variance before being transformed. Feasibility tests using the Kaiser-Meyer-Olkin (KMO) test for sampling adequacy and Bartlett's sphericity test indicate the suitability of the variables for factor analysis, which can be found in Table 3. The KMO value of greater than 0.8 shows that the correlation among the variables is relatively high. The Bartlett's test indicates that the variables' independence assumption should be rejected, and the application of factor analysis was necessary. As a result, the 13 input variables were reduced to four factors by PCA and a varimax rotation (Table 4), which account for $79.95 \%$ of the variance in the input variables. The variables with high componentloading scores (red-colored numbers in Table 4) were used to interpret the factors. The factors were identified as follows: Factor 1 is about urbanization level (population density, age, level of education, and urban population, residential property, and medical care capacity), Factor 2 is defined as economic structure, Factor 3 is income level and ethnicity, and Factor 4 is about employment status and social welfare.

The maps of the four factors for the 105 counties are shown in Fig. 2. From Fig. 2a, we can see that the counties with high Factor 1 score are mainly in highly urbanized
Table 3 The result of KMO and Bartlett's test

\begin{tabular}{lc}
\hline Kaiser-Meyer-Olkin measure of sampling adequacy & 0.83 \\
Bartlett's test of sphericity & \\
Approx. Chi square & 1219.91 \\
df & 78.00 \\
Sig. & 0 \\
\hline
\end{tabular}

Table 4 Rotated component matrix result

\begin{tabular}{|l|r|r|r|r|}
\hline & \multicolumn{4}{|c|}{ Component } \\
\cline { 2 - 5 } & \multicolumn{1}{|c|}{1} & \multicolumn{1}{|c|}{2} & \multicolumn{1}{c|}{3} & \multicolumn{1}{c|}{4} \\
\hline PopDensity & $\mathbf{0 . 8 5}$ & -0.20 & -0.20 & 0.14 \\
RtoEthPop & -0.21 & -0.03 & $\mathbf{0 . 9 0}$ & -0.07 \\
PtoPopAge15-64 & $\mathbf{0 . 6 9}$ & 0.41 & -0.13 & 0.09 \\
PtoEduSec & $\mathbf{0 . 8 9}$ & 0.30 & 0.16 & -0.03 \\
RtoUrbanPop & $\mathbf{0 . 8 7}$ & 0.32 & 0.12 & 0.08 \\
RtoEmpPop & -0.01 & 0.40 & 0.03 & $\mathbf{0 . 5 9}$ \\
PPriIndus & -0.53 & $-\mathbf{0 . 7 3}$ & -0.19 & -0.09 \\
PSecIndus & 0.15 & $\mathbf{0 . 8 8}$ & -0.11 & 0.08 \\
GDPperCapita & $\mathbf{0 . 7 5}$ & 0.51 & 0.09 & 0.24 \\
AvWages & 0.48 & 0.06 & $\mathbf{0 . 6 8}$ & 0.23 \\
PCSvgsDpstB & $\mathbf{0 . 9 4}$ & 0.20 & 0.05 & 0.06 \\
PCHospBed & $\mathbf{0 . 5 3}$ & 0.51 & 0.37 & 0.09 \\
PCSWBed & 0.17 & -0.05 & 0.02 & $\mathbf{0 . 8 8}$ \\
\hline
\end{tabular}

Extraction method: principal component analysis, rotation method: varimax with Kaiser normalization

Red-colored numbers represent the highest component-loading scores for each variable

metropolitan areas, such as the metropolitan areas of Chengdu, Mianyang, Deyang, Yibin, Yaan, and Luzhou, and the counties surrounding these urban areas (Fig. 2a). The map of Factor 2 (Fig. 2b) shows economic dependency 
Fig. 2 Extracted factors from PCA and varimax rotation:

a Factor 1, b Factor 2, c Factor 3, and d Factor 4
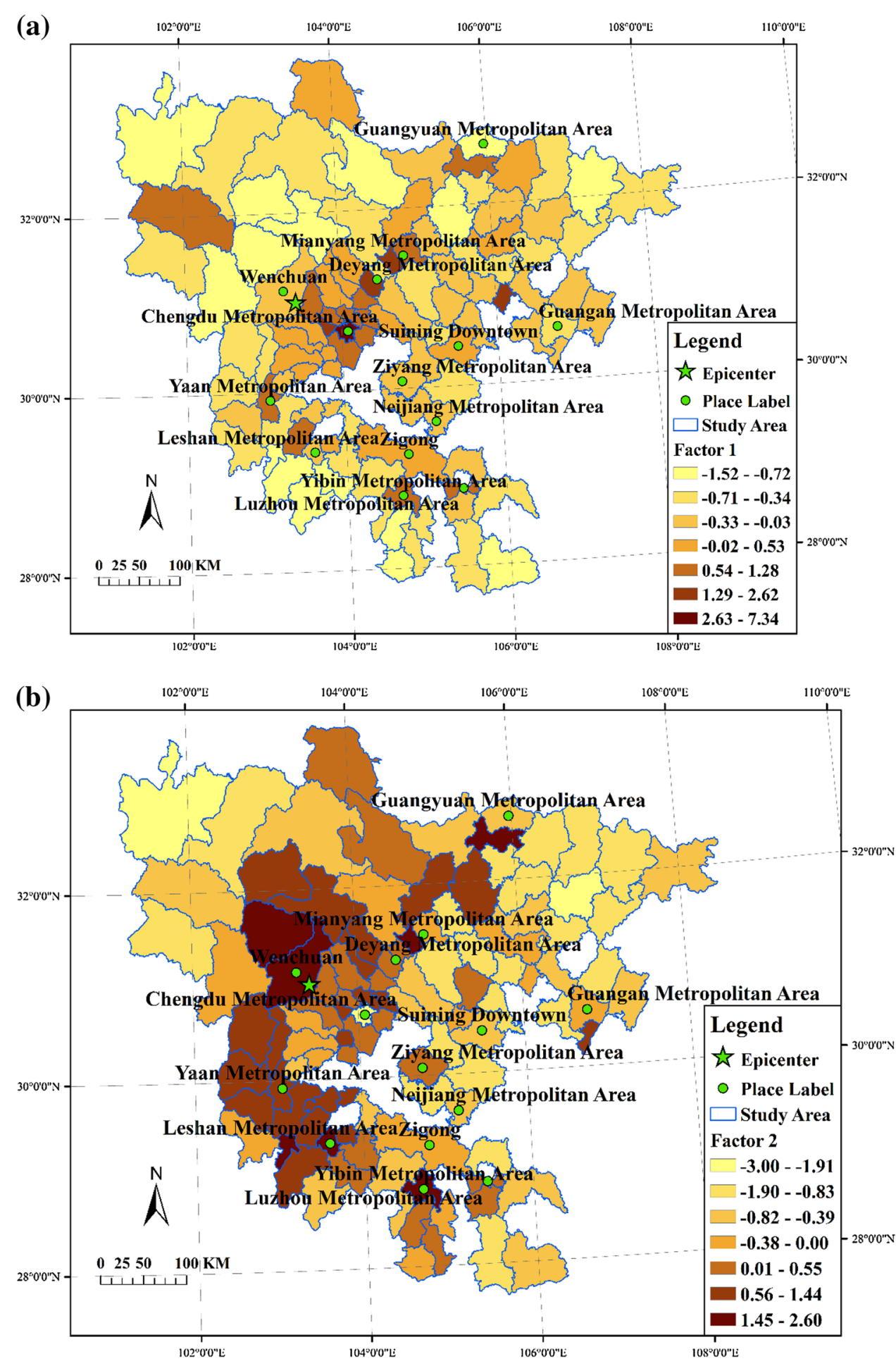

on secondary industries and those areas with secondary industries as the mainstay of their economic base (Wenchuan, Lixian, Maoxian, Yaan, and so on) are mainly found in the west of the region. The counties with primary industries are mostly located in the east. The Chengdu Metropolitan Area has the lowest scores of Factor 2 in the study area-in Chengdu, the proportion of the secondary industries in GDP is very low, and the mainstay of the economic base is the tertiary industry. Factor 3 (Fig. 2c), which combines income and ethnicity, exhibits the distribution of the ethnic minority people and higher income in the 105 counties. The ethnic minority population resides 
Fig. 2 continued
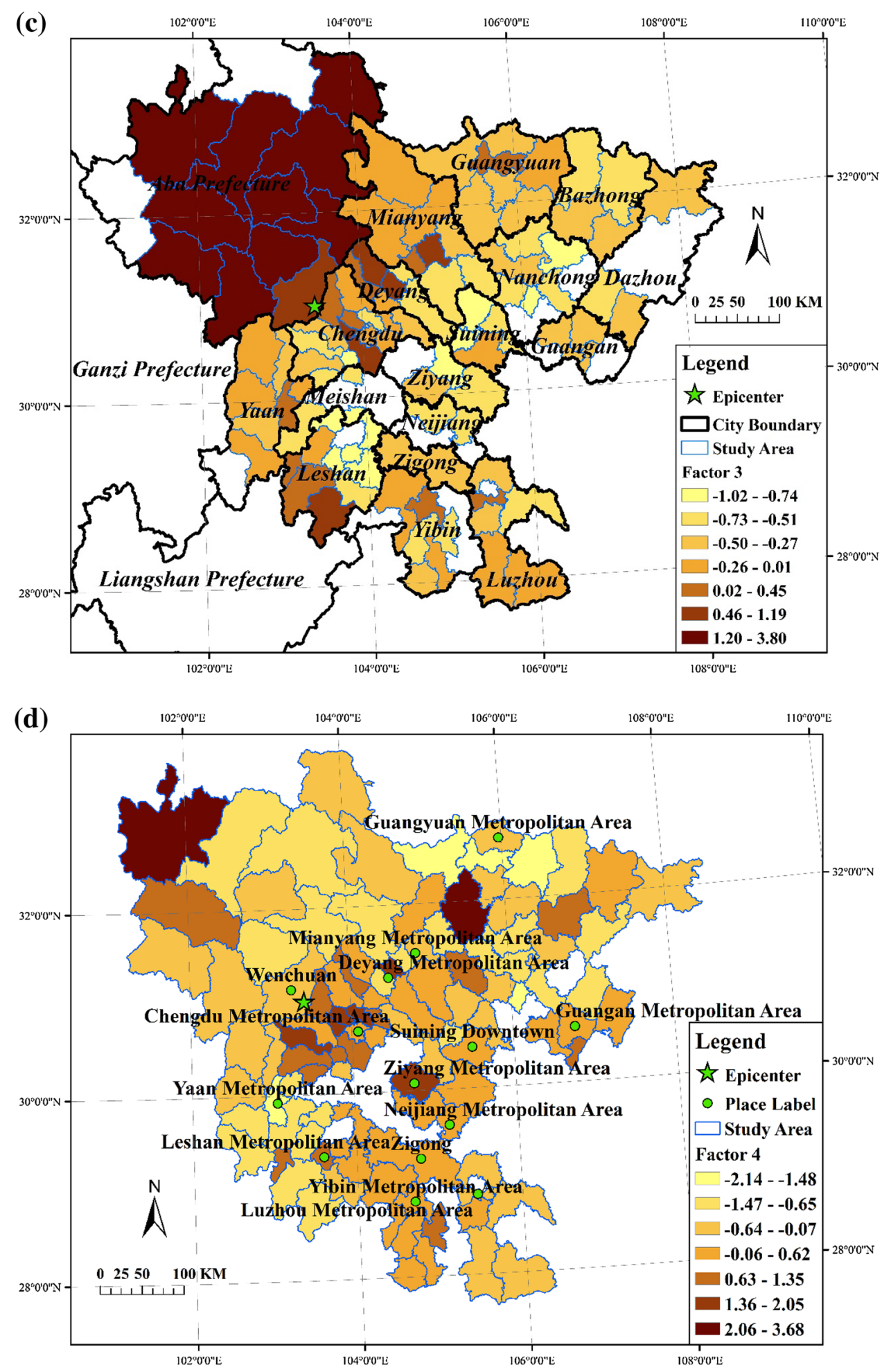

predominantly in the Aba Prefecture. This area is relatively sluggish in economic development due to its high topographic relief and physical isolation from other areas. Two other prefectures in Sichuan Province-Ganzi and Liangshan-are also mainly occupied by minority population.
But due to missing county-level economic loss data, Ganzi and Liangshan are not included in our study, which makes Aba Prefecture a geographically isolated area with respect to Factor 3. In Fig. 2d, areas with a high Factor 4 score (employment and social welfare) are located around the 
Table 5 Ordinary least squares regression statistical report

\begin{tabular}{|c|c|c|c|c|c|c|}
\hline \multirow[t]{2}{*}{ Variables } & \multicolumn{2}{|c|}{ Unstandardized coefficients } & \multirow{2}{*}{$\begin{array}{l}\text { Standardized coefficients } \\
\text { Beta }\end{array}$} & \multirow[t]{2}{*}{ Sig. } & \multirow[t]{2}{*}{ Robust_Pr } & \multirow[t]{2}{*}{ VIF } \\
\hline & $\mathrm{B}$ & Standard error & & & & \\
\hline Intercept & -2.5082 & 1.0427 & & $0.02 *$ & $0 *$ & \\
\hline Intensity & 0.1026 & 0.1905 & 0.0585 & 0.59 & 0.51 & 1.76 \\
\hline Loss per capita & $4.25 \mathrm{E}-06$ & $1.93 \mathrm{E}-06$ & 0.2618 & $0.03 *$ & $0.01 *$ & 2.07 \\
\hline Factor 1 & -0.3633 & 0.1322 & -0.2446 & $0.01 *$ & $0^{*}$ & 1.17 \\
\hline Factor 2 & 0.2550 & 0.1341 & 0.1688 & 0.06 & 0.11 & 1.14 \\
\hline Factor 3 & -0.7472 & 0.1379 & -0.5039 & $0 *$ & $0^{*}$ & 1.26 \\
\hline Factor 4 & 0.0368 & 0.1272 & 0.0246 & 0.77 & 0.78 & 1.06 \\
\hline Akaike's information criterion & 344.87 & & & & & \\
\hline Adjusted r-squared & 0.31 & & & & & \\
\hline
\end{tabular}

metropolitan areas of Chengdu, Deyang, Ziyang, Leshan, and Guangan.

\subsection{Confirmative Analysis with Global Ordinary Least Squares Model}

The four factors from the factor analysis along with the two variables about the earthquake-earthquake intensity and loss per capita-were used as the explanatory variables in a linear regression to examine their relationships with the change in the population growth rate. The change in population growth rate before and after the earthquake event $(\Delta d p)$ was used as the resilience index, that is, the dependent variable of the regression.

The initial round of OLS regression showed there are two outliers: Hanyuan County (OLS residual 10.66) and Mabian County (OLS residual -6.30 ). Because regression models can be severely affected by outliers, we removed these two counties and used only the remaining 103 units in the study area in the following analysis. At the second round of regression with the 103 counties, the least squares regression result (Table 5) shows that the intercept (general level of recovery capability), loss per capita, and Factors 1 and 3 in the model are statistically significant. Loss per capita has a positive coefficient, whereas the intercept and Factors 1 and 3 have negative coefficients. The variance inflation factor (VIF) values, which are used to quantify the severity of multicollinearity in the OLS analysis, do not suggest any multicollinearity among the independent variables. The coefficient of adjusted r-squared for the recovery capability is 0.31 , which suggests a significant amount of unexplained variance by the regression model. The residual map (Fig. 3) shows that the residual has no obvious spatial clusters. The negative sign of the intercept indicates that in general this study area had a significantly lower population growth rate after the earthquake than the pre-seismic event rate. This change was very likely due to the earthquake disaster. The negative sign of Factor 1 indicates that the resilience to the earthquake disaster may be inversely related to the degree of urbanization. Areas with a higher density of human construction may need more time to rebuild than the rural areas.

The coefficient of Factor 3 is also significantly negative, suggesting that the ethnic minorities have less resilience to earthquakes. Similar findings about ethnic minority groups were reported before but in different study areas in metropolitan areas in the eastern and southern US (Cutter et al. 2003). In fact, many scholars have suggested that cultural obstacles and marginalization of ethnic minorities would have an adverse effect on these communities' social vulnerability, resistance to disasters, and the ability to recover (Cutter et al. 2003). In Southwest China, a high percentage of ethnic minority communities often live in isolated areas, are poor with limited income and low levels of economic development, and exhibit a lack of infrastructure as well as limited access to communication technology (Shan 2010).

According to the disaster literature (Cutter et al. 2003; Bruneau et al. 2003), areas with more damage and greater economic loss may need a longer time to recover. This is not the case with the Wenchuan Earthquake area in Southwest China, however, as illustrated by our regression model. Loss per capita from the earthquake has a significant positive association with resilience in our case study. This apparent counterintuitive result can be explained by the fact that those counties that suffered more losses have received more resources from the government for reconstruction. The prioritized allocation of resources for reconstruction, labor, and funds from society and government might have contributed to a faster recovery and thus created apparent higher community resilience from the seismic disaster. Economic loss per capita is still the main criteria for prioritizing disaster relief and recovery by the government (Guo 2012). Our model shows that communities and individuals who really need more assistance may well be located in ethnic monitory and densely built-up areas. The standardized coefficients of the independent variables ranked from high to low by their magnitude are: Factor 3, loss per capita, Factor 1, Factor 2, 
Fig. 3 Residuals of the ordinary least squares regression model

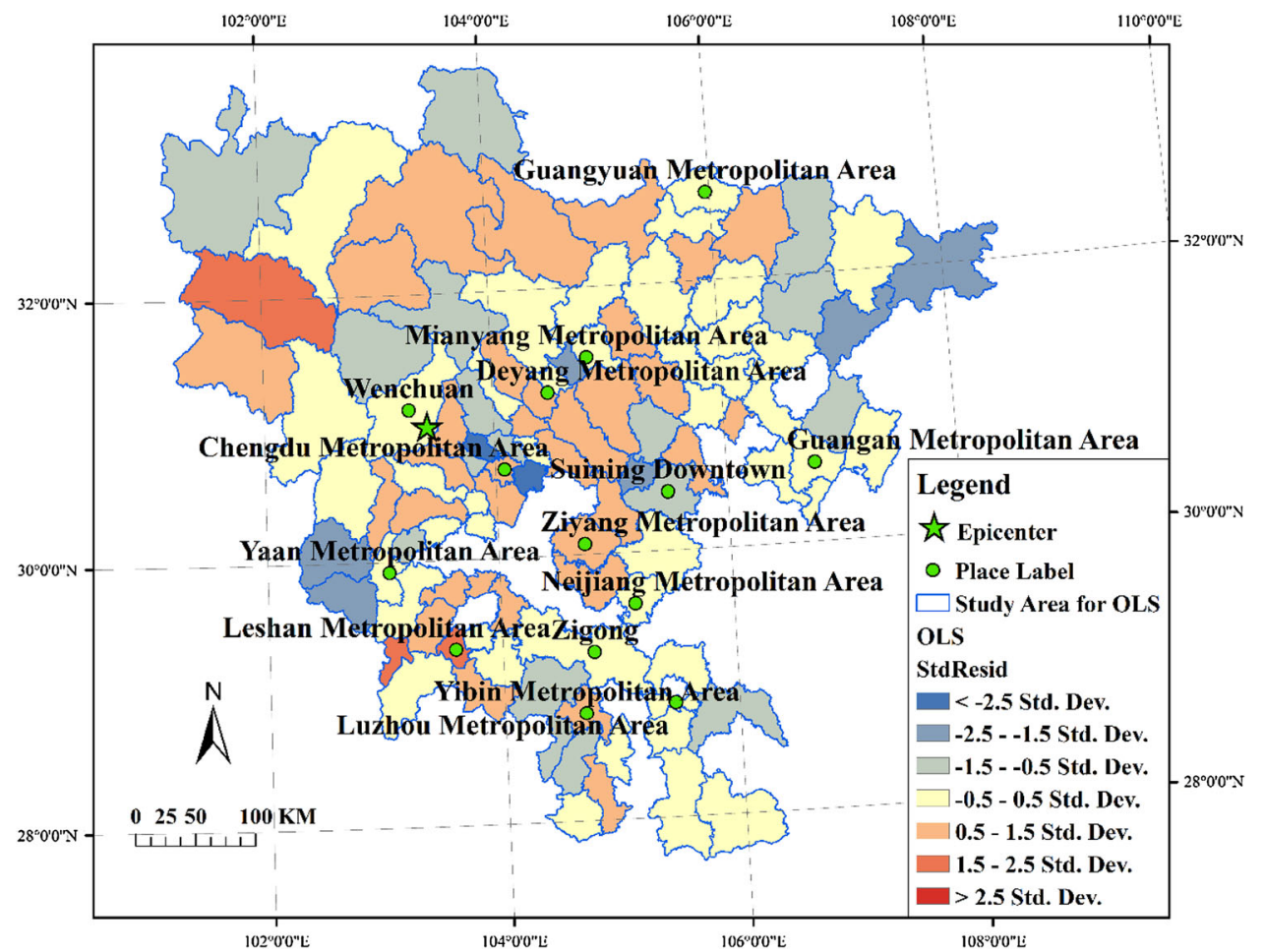

intensity, and Factor 4. Because Factor 2, Factor 4, and intensity are not significant, we do not provide deeper discussion on these variables.

\subsection{Explorative Analysis with the Geographically Weighted Regression Model}

In addition to the classic OLS regression model, localized regression models such as a GWR could provide knowledge about the spatial stationarity of the model and spatial pattern of the coefficients (Unwin 1996; Fotheringham et al. 1998). Unlike the OLS method, which estimates the global behavior of coefficients regardless of geographical settings and locations (Panik 2009), GWR estimates the local parameters $\hat{\beta}(i)$ at location $i$ that minimize local regression error constrained by a geographically weighted matrix $w_{i}$ (Hastie and Tibshirani 1990; Fotheringham et al. 1998, 2003; Panik 2009):

$\hat{\beta}(i)=\left(X^{T} W(i) X\right)^{-1} X^{T} W(i) y$,

where $W(i)=\left(\begin{array}{cccc}W_{i 1} & 0 & \cdots & 0 \\ 0 & W_{i 2} & \cdots & 0 \\ \vdots & \vdots & \ddots & \vdots \\ 0 & 0 & \cdots & W_{i n}\end{array}\right)$ is a matrix of weights specific to location $i$ and the values are between 0 and $1 . W_{i n}$ is the weight given to data point $n$ by the impact between location $i$ and location $n$. The weights are usually modeled as a Gaussian-shape distance decay function with higher weights assigned to closer locations (Fotheringham et al. 2003).

We ran the GWR analysis with the same variables selected for the global OLS model. The bandwidth parameter of the GWR model is set to be adaptive. The adaptive bandwidth is especially useful to deal with spatial heterogeneity. Calibration of bandwidth is based on the method of Akaike information criterion (AIC) (Akaike 1974). The AIC method can find the best model among a group of the candidates that has the maximum likelihood:

$\mathrm{AIC}=2 k-\ln (L)$,

where $L$ is the likelihood function of the model fitness, $k$ is the number of parameters. Therefore, the best bandwidth parameter is the one with the minimum AIC value. The statistical summary report of the GWR model is shown in Table 6. Figure 4 maps the residuals of the GWR model. The mean AIC is 346.12 in the GWR model, achieving a slightly better goodness-of-fit. Similarly, the adjusted r-squared slightly increased from 0.31 (OLS) to 0.333 (GWR), which indicates that there is a marginal gain in explanatory power by the GWR model with the use of localized data samples. Figure 5 displays maps of the local r-squared. The figure shows that local r-squared derived by the GWR model decrease gradually from northwest to southeast in the study area.

Figure 6 shows the spatial patterns of the coefficients for intercept, intensity of earthquake, economic loss per capita, Factors 1-4. Local $p$-values were used to determine 
Table 6 Geographically weighted regression statistical summary report

\begin{tabular}{|c|c|c|c|c|c|}
\hline Variables & Min & $25 \%$ Quartile & $50 \%$ Quartile & $75 \%$ Quartile & $\operatorname{Max}$ \\
\hline Intercept & -4.430 & -2.933 & -2.168 & -1.796 & -1.494 \\
\hline Intensity & -0.081 & -0.019 & 0.049 & 0.171 & 0.391 \\
\hline Loss per capita & $4.33 \mathrm{E}-06$ & $4.71 \mathrm{E}-06$ & $5.01 \mathrm{E}-06$ & $5.4 \mathrm{E}-06$ & $5.9 \mathrm{E}-06$ \\
\hline Factor 1 & -0.446 & -0.422 & -0.400 & -0.366 & -0.310 \\
\hline Factor 2 & -0.048 & 0.039 & 0.126 & 0.225 & 0.345 \\
\hline Factor 3 & -0.889 & -0.845 & -0.810 & -0.781 & -0.735 \\
\hline Factor 4 & -0.057 & -0.010 & 0.029 & 0.081 & 0.146 \\
\hline Akaike's information criterion & 346.12 & & & & \\
\hline Adjusted r-squared & 0.333 & & & & \\
\hline
\end{tabular}

Fig. 4 Residuals of the geographically weighted regression model

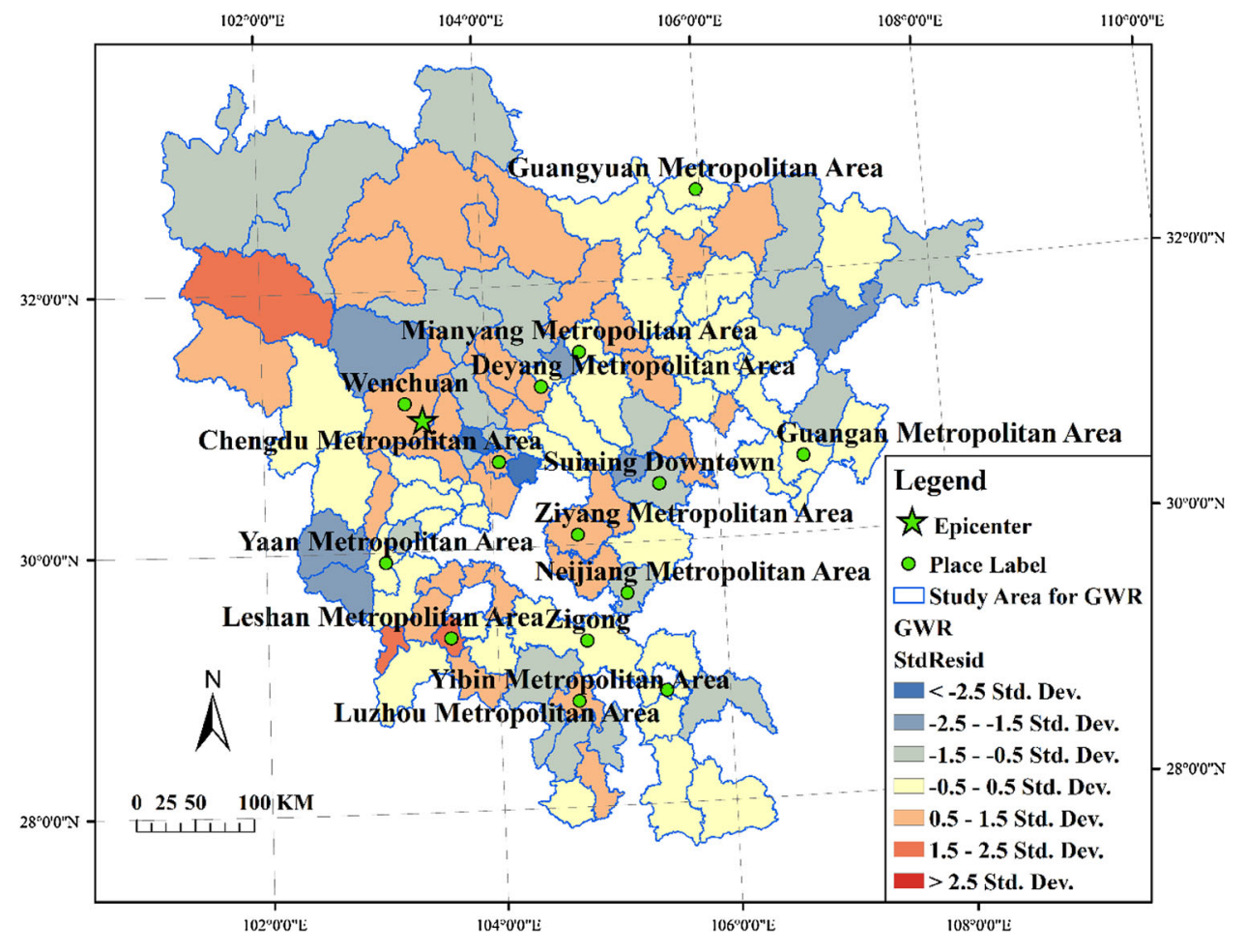

whether the coefficients were significant (shaded area) or not (non-shaded area). The intercepts are higher in the south than the north of the area. This distribution indicates the generally higher recovery capability of the counties in the southern part of Sichuan Province (Fig. 6a). Although the OLS model did not find any significant association between the earthquake intensity and resilience, the GWR model found the coefficients are significant for four counties located in the Guangyuan Metropolitan Area in northeast Sichuan (Fig. 6b). The coefficients of loss per capita are significant and positive for all the counties in the study area, but there is a downward spatial trend from the west towards the east (Fig. 6c). The coefficients of Factor 1 are the strongest near the metropolitan areas of Chengdu, Deyang, and Mianyang (Fig. 6d). The coefficients of Factor 2 are positive throughout the study area, but only are significant in a few southern areas such as Luzhou, Yibin, Zigong, and Leshan. The result is consistent with the global OLS regression. Similar to the OLS model, Factor 3 in the GWR model generally has negative coefficients. Nevertheless, the GWR model is able to describe the spatial distribution of the coefficients of Factor 3. As shown in Fig. 6f, the highest coefficients of Factor 3 are found in the southwestern part of the study area, especially in Yaan and Leshan areas, followed by Aba Prefecture. Also consistent with the OLS model, there are no significant coefficients of 
Fig. 5 Coefficients of determination (R-squared) from geographically weighted regression

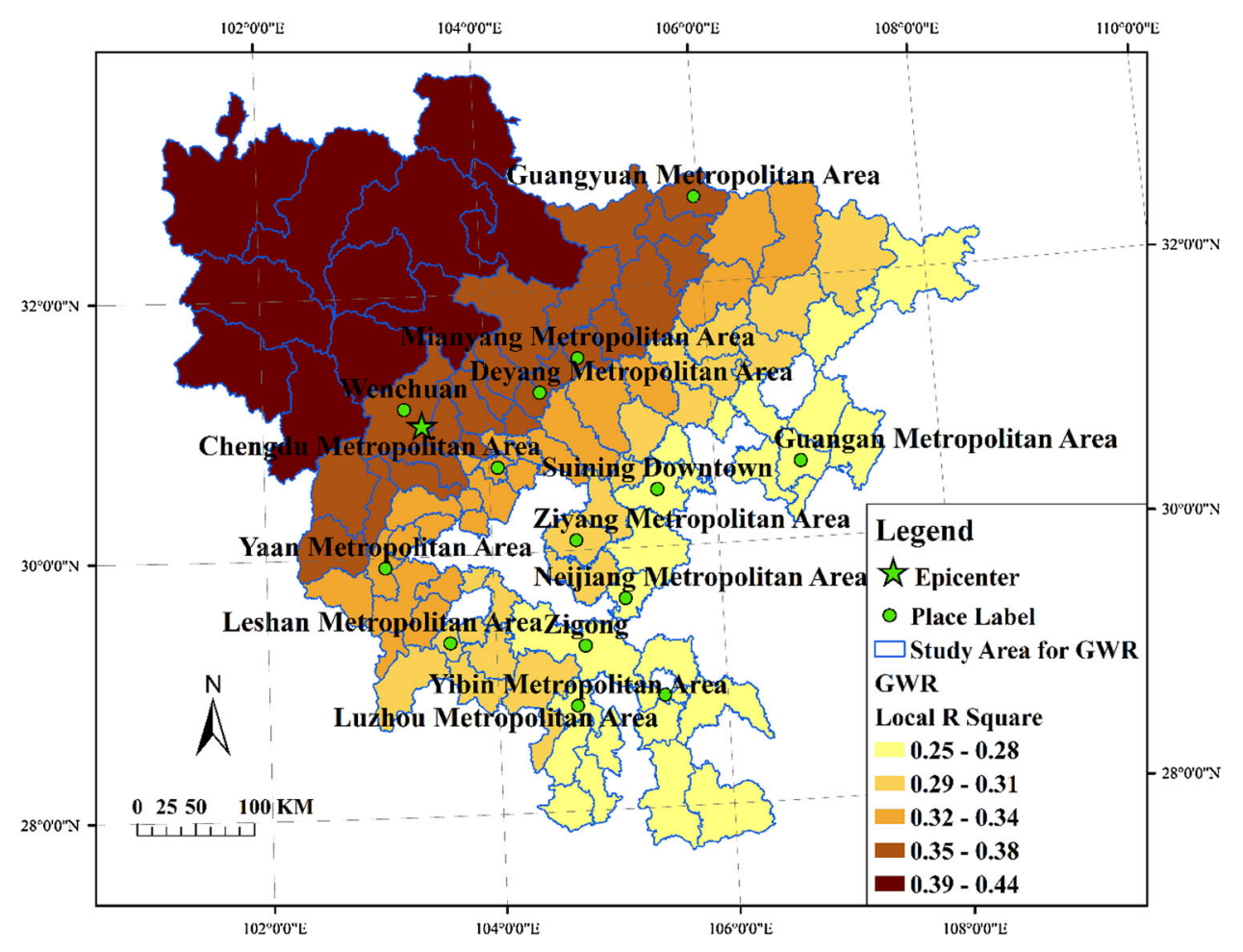

Factor 4 at the $p<0.10$ level in the study area. Therefore, we do not include Factor 4 in our further discussion.

\subsection{Spatial Clusters of the GWR Coefficients}

The coefficient maps produced by the GWR model show certain spatial continuities (Fig. 6), because the coefficients were optimized by local samples that are naturally spatially autocorrelated. Overlaying the coefficient maps for a cluster analysis would help identify boundaries of the underlying regionalization determined naturally by social and economic processes.

K-means cluster analysis (Hartigan and Wong 1979) is an unsupervised classification method commonly used to identify the natural groups (classes) among the data samples. The input variables are the standardized outputs from the GWR model, including the significant variable coefficients, their associated $p$-values, and the local r-squared. The number of preset classes $(k)$ is an arbitrarily selected parameter for the K-means algorithm, which needs a user's specification or through optimization. A common practice of optimization is to select the optimal $k$ value by using the AIC method (Milligan and Cooper 1985). In our analysis, the $k=4$ gave the minimum AIC. Therefore, the study area was partitioned to four different regions by the K-means algorithm. The regions are shown in Fig. 7 and their statistics are summarized in Table 7 . The mean values of the coefficients in each of the four regions depict the strength of the association of each independent variable with community resilience. The stronger the association, the better the possibility that relevant disaster relief policies will enhance resilience. Therefore, we can suggest following localized policies to improve community resilience to seismic hazards:

(1) Region 1 (the blue area in Fig. 7) mainly includes the counties in the northeastern part of the study area. In this region, intercept, loss per capita, and Factors 1 and 3 are significant. It has higher coefficients of intensity, loss per capita, and Factor 1, and lower coefficients of intercept and Factor 3 than other regions. Most counties are located relatively far from the epicenter of the earthquake. The GWR coefficients show that the negative association of the earthquake damage with the recovery rate was stronger than other regions. In order to achieve a better recovery rate in this area, it would be effective to allocate more recovery resources to those counties that suffered higher losses. The economic development level of this region is medium. The negative coefficients of Factor 3 (income level and ethnicity) lead to the conclusion that the minorities predominant in this area are less resilient to earthquake disasters than the general population. This is consistent with Cutter et al. (2003), that is, ethnic minority populations are most likely to be isolated by social or cultural barriers (Cutter et al. 2003, 2008), which would make them less resilient to disasters. 
Fig. 6 GWR coefficients: a intercept, b earthquake intensity, c economic losses per capita, d Factor 1, e Factor 2, f Factor 3, and $\mathbf{g}$ Factor 4
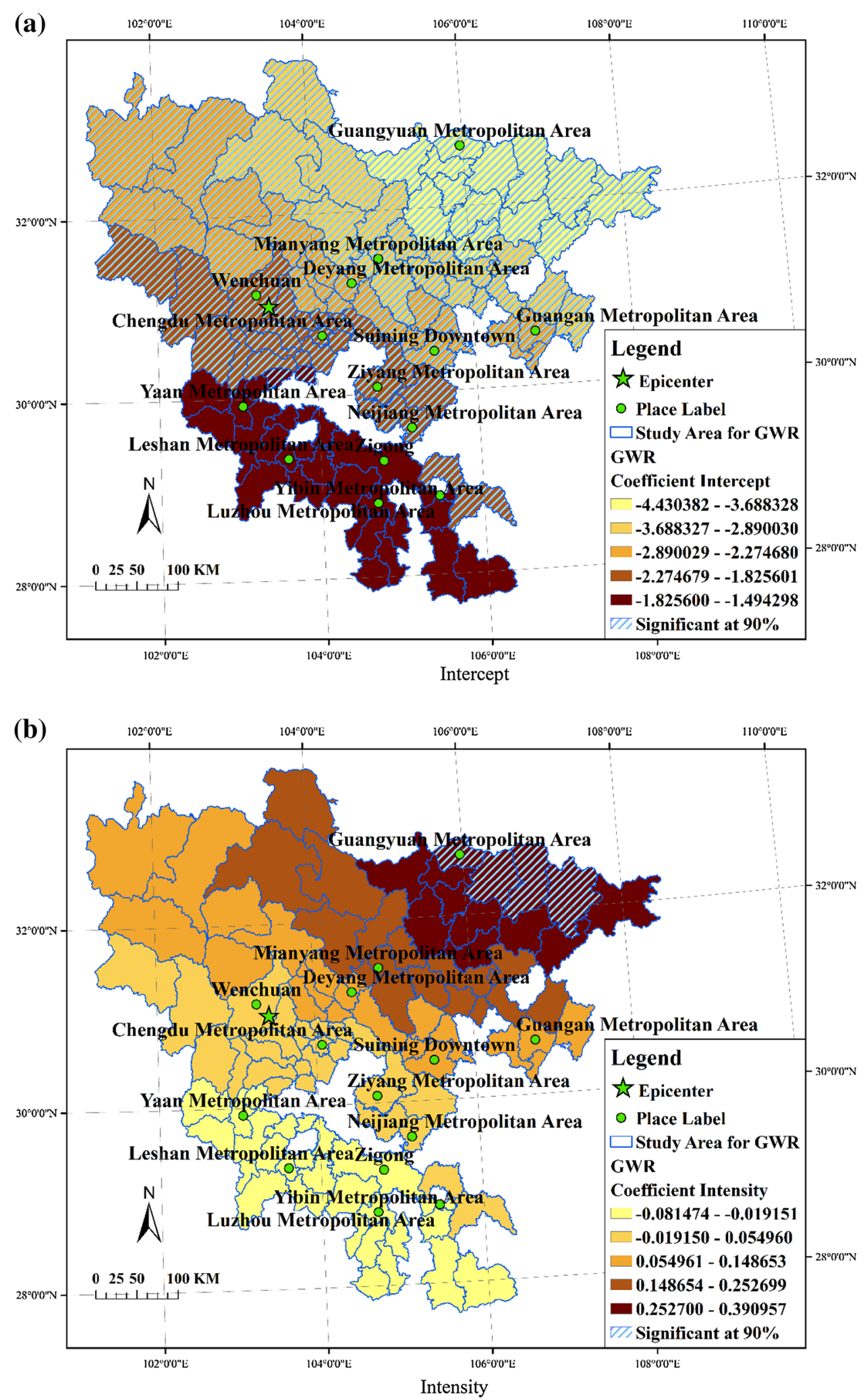

(2) Region 2 (the red area in Fig. 7) includes the counties in the southeastern segment of the study area. Here regression intercepts are not significant, an indication that this area has weak resilience in general. Factor 2 coefficients are positive and significant. Figure $6 \mathrm{e}$ reveals that Region 2 is unique in that it is the only 
Fig. 6 continued
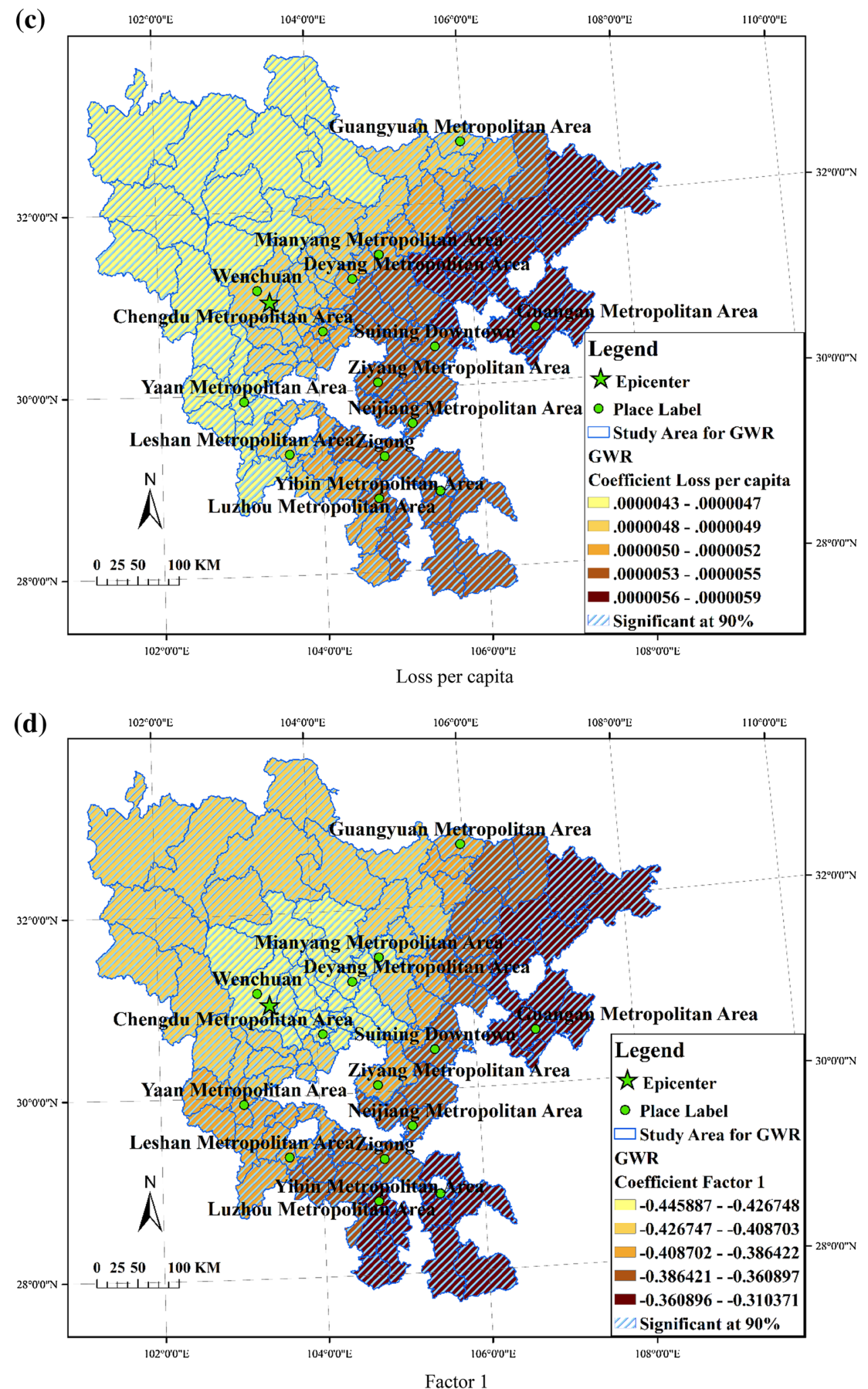

area with significant Factor 2 coefficients. Factor 2 reflects economic dependency on secondary industries. The positive sign of Factor 2 suggests that the society supported by the secondary industries is more resilient to earthquake disasters than the general population. Other than Factor 2, this region has 
Fig. 6 continued
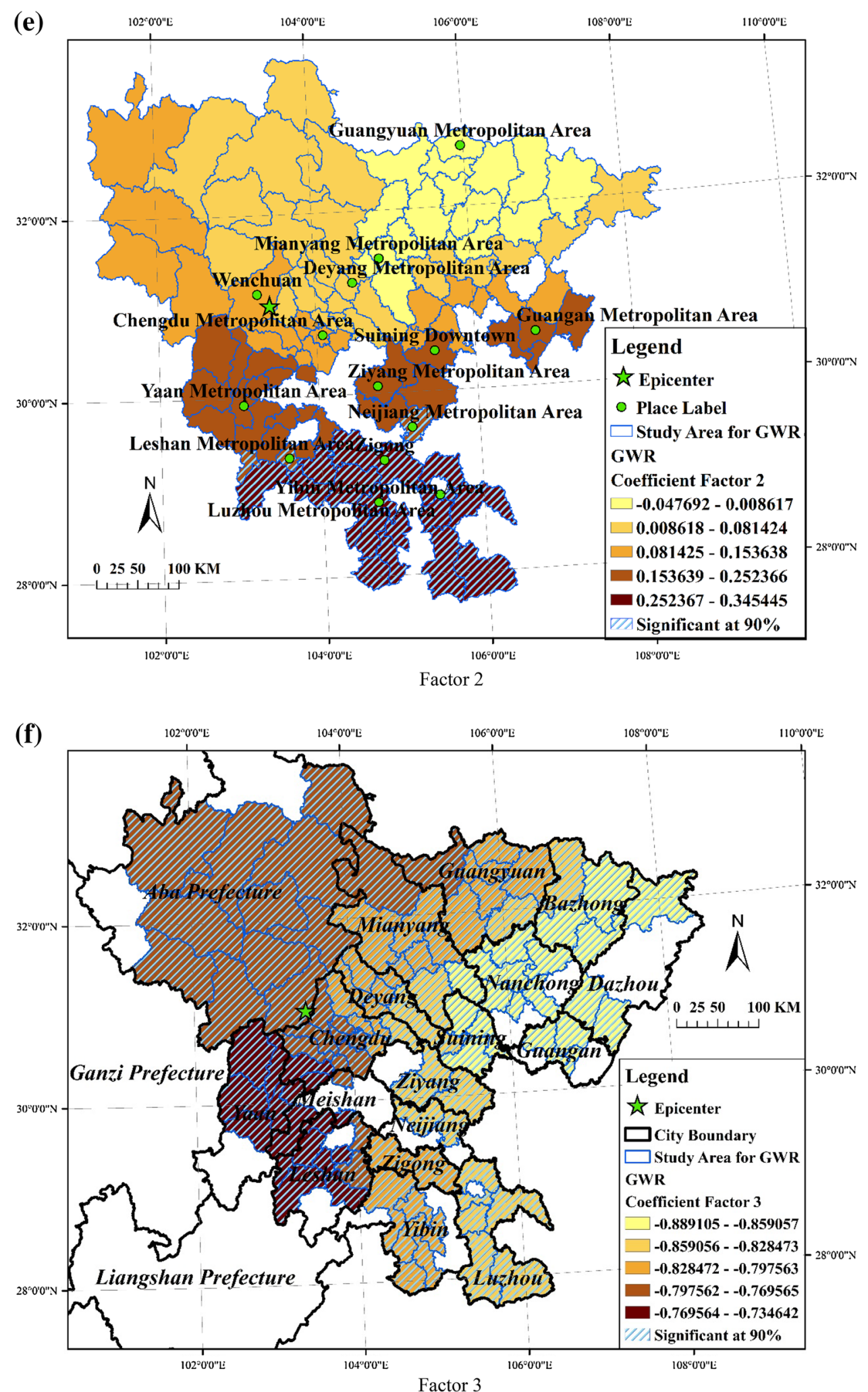

medium level coefficients of other factors among the regions.

(3) Region 3 (the green area in Fig. 7) is located in the western half of the study area. In Region 3, four variables are significant: intercept, loss per capita, Factors 1 and 3. Among all regions, the resilience of Region 3 has the slightest influence from earthquake loss and the strongest influence from Factor 1- 
Fig. 6 continued

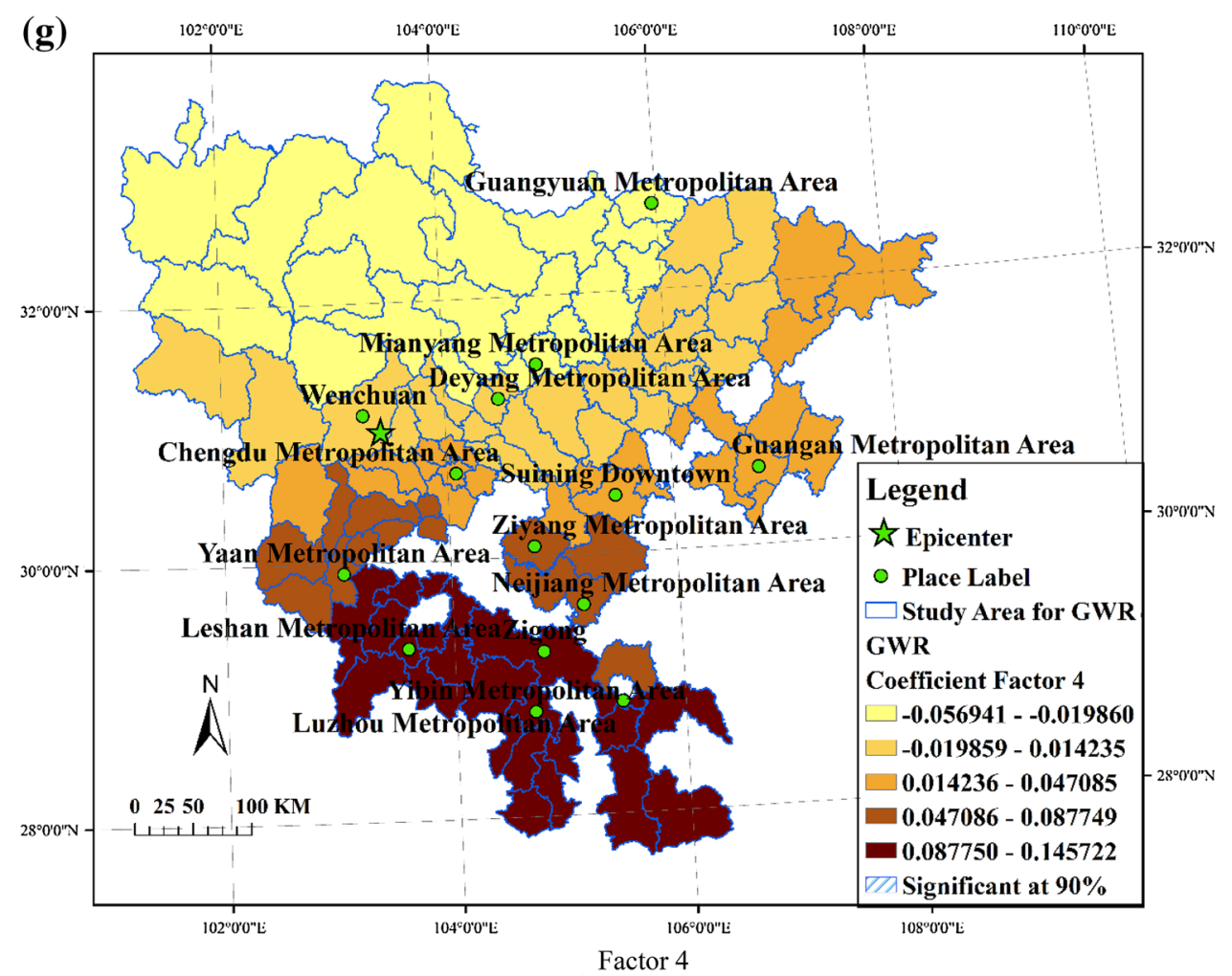

Fig. 7 Regions classified by K-means cluster analysis using local coefficients derived by GWR $(k=4)$

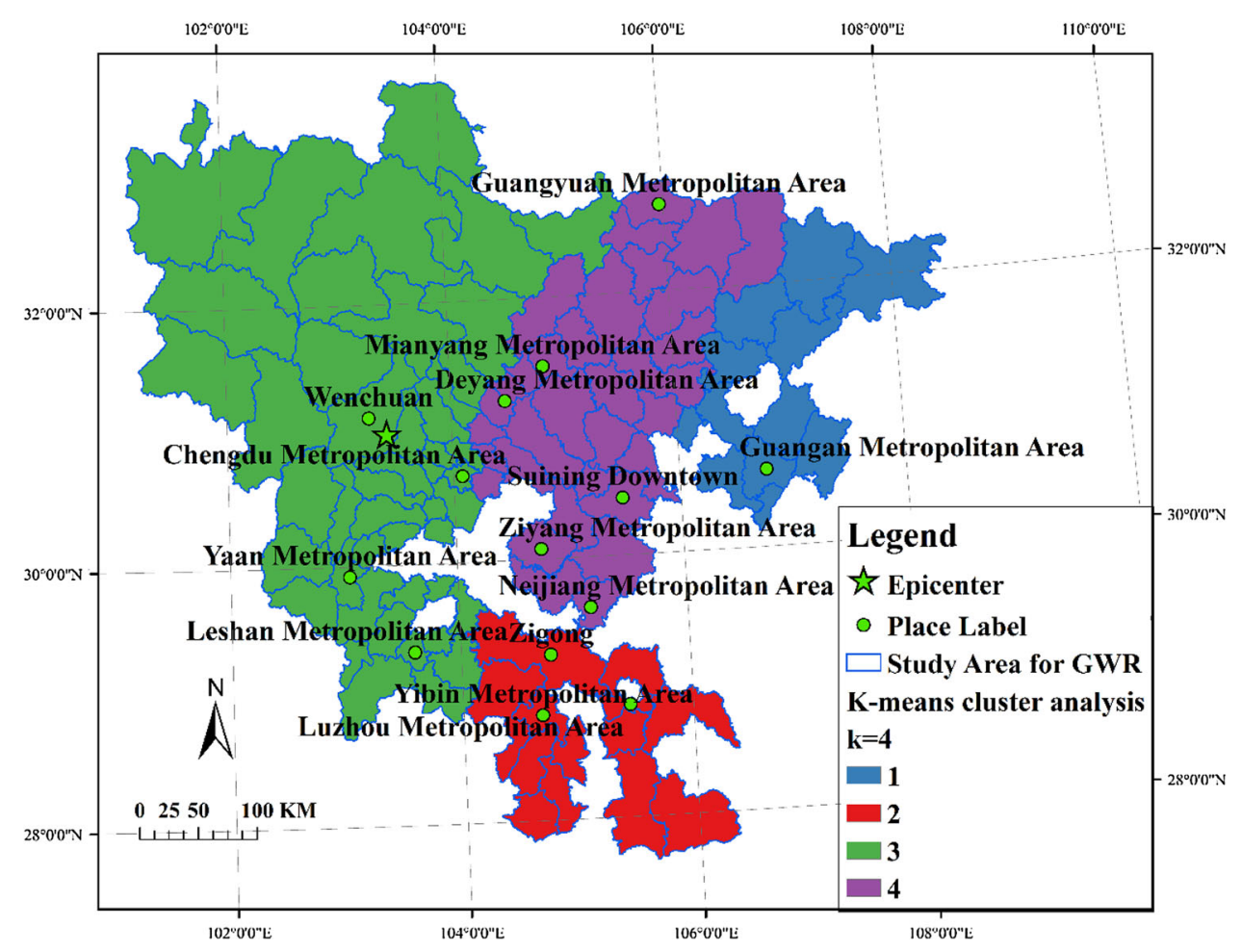

urbanization. In fact, this region suffered the most physical damage from the earthquake of the four regions. The socioeconomic situation of the local residents varied from well-to-do in Chengdu,
Mianyang, and Deyang Metropolitan Areas to the underdeveloped surrounding rural areas occupied by non-Han ethnic minority populations. It is the dominant factor of reduced resilience. Language and 
Table 7 Characteristics of clusters identified by the K-means cluster analysis

\begin{tabular}{|c|c|c|c|c|c|c|c|c|c|c|}
\hline \multirow[t]{3}{*}{ Regions } & \multirow[t]{3}{*}{$n$} & \multicolumn{9}{|c|}{ Mean of parameter estimates } \\
\hline & & \multirow[t]{2}{*}{ Local R-squared } & \multicolumn{4}{|c|}{ Coefficients } & \multicolumn{4}{|c|}{ Local $p$-values } \\
\hline & & & Intercept & Loss per capita & Factor 1 & Factor 3 & Intercept & Loss per capita & Factor 1 & Factor 3 \\
\hline 1 & 12 & -1.13 & -1.10 & 1.63 & 1.53 & -1.64 & -0.99 & -1.12 & 1.69 & 0 \\
\hline 2 & 13 & -1.12 & 0.94 & 0.53 & 1.36 & -0.38 & 1.38 & -0.40 & 1.24 & 2.30 \\
\hline 3 & 46 & 0.65 & 0.45 & -0.91 & -0.61 & 0.90 & 0.34 & 0.84 & -0.58 & -0.43 \\
\hline 4 & 32 & -0.06 & -0.61 & 0.47 & -0.25 & -0.53 & -0.68 & -0.62 & -0.31 & -0.32 \\
\hline \multicolumn{2}{|c|}{ F-statistics* } & 64.6460 & 33.18 & 28.53 & 123.11 & 76.30 & 123.82 & 41.44 & 51.02 & 82.42 \\
\hline \multicolumn{2}{|l|}{ Sig. } & 0 & 0 & 0 & 0 & 0 & 0 & 0 & 0 & 0 \\
\hline
\end{tabular}

* F statistics test: ANOVA test on the differences between the mean of local coefficients in the four clusters

cultural barriers as well as physical isolation caused by the topography made recovery difficult for those minority and low-income populations. More resources should be allocated to these regions when planning for disaster preparedness, relief, and recovery, than the general population.

(4) Region 4 (the purple area in Fig. 7) constitutes the central transitional zone of the study area. In this region intercept, loss per capita, and Factors 1 and 3 are significant but the magnitudes are not very strong. Earthquake damage in this region has not had much impact on resilience. Overall, this region's ethnic minority population is a major negative impact factor on resilience. In other words, lower resilience is found in areas with more ethnic minority populations. Policymakers shall focus more on helping ethnic minority population improve their social and economic status.

\section{Discussion and Conclusions}

Although the result of the OLS regression analysis in this study confirms the relationship between the selected socioeconomic factors and community resilience to seismic hazard, the GWR model enables deeper exploration of geographical heterogeneity in the study area. General statistical methods have been criticized for their attempt to generalize human objects while neglecting the spatial structure of society. The use of a location-based model, GWR, compensates for the weakness of the pure statistical model that measures the correlation between a dependent variable and independent variables over the entire study area. For policy making, the spatial patterns of the coefficients can provide useful knowledge about local needs. In other words, the global regression answers generalized questions such as "Is factor $x$ significant everywhere?", while the GWR model answers geographically specific questions such as "Is factor $x$ significant here?" Location-based decisions can help allocate the limited resources available for disaster mitigation programs for their best use. Therefore, the use of geographical analysis based on local regression models such as GWR can effectively assist decision making in the disaster management sciences, especially in areas where the economic and social conditions of the society are highly variable by locations.

As a local regression model, GWR is able to account for the spatial continuity of sample data. We used GWR to explore the relationships between socioeconomic variables and resilience. However, several critiques of GWR exist. Most prominent are claims that GWR models lack a rigorous, formal statistical analysis (Congdon 2003; LeSage 2004; Wheeler and Calder 2007), and local collinearity (Wheeler and Tiefelsdorf 2005; Yu et al. 2009). We do not rate GWR models higher than traditional OLS regression models. Both model forms were helpful to our research in understanding the variables and problem to be explained. We used the OLS regression to confirm the selection of variables and GWR to explore the spatial pattern of the regression coefficients. Our tests showed that no local collinearity existed in our data, which was indicated by the small local condition numbers in the regression report.

Furthermore, the quantitative methods used in our study compare favorably with those used by other social science and humanity studies. We used the regionalization analysis to partition the study area into multiple sections characterized by relatively uniform coefficient values generated by the local regression model. This is similar to what has been used in regional geography research that studies the unique combination of characteristics of an area (Peet 1998). Despite the similarity in the form and the descriptive nature, our approach is fundamentally different from those of the traditional regional social science that were criticized for their lack of scientific evidence to define a "region." The regions defined by the traditional approach are subjective and scientifically unpredictable. In contrast, our approach is based on the 
quantitative methodology that underlies regression models-our regional divisions are empirically defined. Specifically, in this study we used the K-means clustering method to define regions. The regions created by our regionalization analysis are predictable and scientifically justifiable, and essentially it is the GIS that makes such an approach possible. Hence, one of the contributions of this article is to illustrate and promote the use of GIS-based spatial analysis and statistics in natural disaster studies.

A study of society's resilience to a major earthquake event was illustrated using regression models. In the study area, earthquakes are a tremendously destructive threat to the community and this geological hazard has occurred at fairly regular time intervals ( $\mathrm{Li}$ et al. 2015b). The study area included over 105 counties in Sichuan, southwestern China, which were hit in 2008 by the Wenchuan Earthquake. A GWR model revealed the spatially varying strength of the area's socioeconomic factors in relation to the social resilience of local communities to seismic hazard. Based on spatial analysis in a GIS, we were able to infer location-sensitive decisions for allocation of disaster relief resources provided by the government. This invokes a new approach to spatial decision support in disaster management science. In this article, we also illustrated a general analytical framework for community resilience assessment. We anticipate that similar approaches will be applied to other disaster management studies. In future research, it would be beneficial to add a time dimension to our data for more comprehensive analyses, which enables longitudinal trend analyses of disaster events and the study of the coupled human-nature system and disaster-response system in a spatiotemporal framework.

Acknowledgments This material is partially based upon Project funded by the China Postdoctoral Science Foundation (Award No. 2016M592647). Any opinions, findings, and conclusions or recommendations expressed in this material are those of the authors and do not necessarily reflect the views of the funding agencies.

Open Access This article is distributed under the terms of the Creative Commons Attribution 4.0 International License (http://crea tivecommons.org/licenses/by/4.0/), which permits unrestricted use, distribution, and reproduction in any medium, provided you give appropriate credit to the original author(s) and the source, provide a link to the Creative Commons license, and indicate if changes were made.

\section{References}

Adger, W.N., T.P. Hughes, C. Folke, S.R. Carpenter, and J. Rockstrom. 2005. Social-ecological resilience to coastal disasters. Science 309(5737): 1036-1039.

Akaike, H. 1974. A new look at the statistical model identification. IEEE Transactions on Automatic Control AC-19(6): 716-723.

Bevington, J.S., A.A. Hill, R.A. Davidson, S.E. Chang, A. Vicini, B.J. Adams, and R.T. Eguchi. 2011. Measuring, monitoring, and evaluating post-disaster recovery: A key element in understanding community resilience. Proceedings of ASCE Structures Congress 2011, American Society of Civil Engineers, 2033-2043.

Brown, D.D., and J.C. Kulig. 1996. The concepts of resiliency: Theoretical lessons from community research. Health and Canadian Society 4(1): 30-50.

Bruneau, M., S.E. Chang, R.T. Eguchi, G.C. Lee, T.D. O'Rourke, A.M. Reinhorn, M. Shinozuka, K. Tierney, W.A. Wallace, and D. von Winterfeldt. 2003. A framework to quantitatively assess and enhance the seismic resilience of communities. Earthquake Spectra 19(4): 733-752.

Brunsdon, C., A.S. Fotheringham, and M.E. Charlton. 1998. Geographically weighted regression-modelling spatial non-stationarity. Journal of the Royal Statistical Society: Series D (The Statistician) 47(3): 431-443.

Chang, S.E. 2010. Urban disaster recovery: A measurement framework and its application to the 1995 Kobe Earthquake. Disasters 34(2): 303-327.

Chatfield, C., and A.J. Collins. 1980. Introduction to multivariate analysis. London: Chapman and Hall.

Cloke, P., C. Philo, and D Sadler. 1991. Approaching Human Geography. London: Chapman.

Congdon, P.D. 2003. Modelling spatially varying impacts of socioeconomic predictors on mortality outcomes. Journal of Geographical Systems 5(2): 161-184.

Cutter, S.L., B.J. Boruff, and W.L. Shirley. 2003. Social vulnerability to environmental hazards. Social Science Quarterly 84(2): 242-261.

Cutter, S.L., L. Barnes, M. Berry, C. Burton, E. Evans, E. Tate, and J. Webb. 2008. A place-based model for understanding community resilience to natural disasters. Global Environmental Change 18(4): 598-606.

Cutter, S.L., C.G. Burton, and C.T. Emrich. 2010. Disaster resilience indicators for benchmarking baseline conditions. Journal of Homeland Security and Emergency Management 7(1). Article no. 51.

Finch, C., C.T. Emrich, and S.L. Cutter. 2010. Disaster disparities and differential recovery in New Orleans. Population and Environment 31(4): 179-202.

Fotheringham, A.S., P.J. Densham, and A. Curtis. 1995. The zone definition problem in location-allocation modeling. Geographical Analysis 27(1): 60-77.

Fotheringham, A.S., M.E. Charlton, and C. Brunsdon. 1998. Geographically weighted regression: A natural evolution of the expansion method for spatial data analysis. Environment and Planning A 30(11): 1905-1927.

Fotheringham, A., C. Bunsden, and M. Charlton. 2000. Quantitative geography. London: Sage.

Fotheringham, A.S., C. Brunsdon, and M.E. Charlton. 2003. Geographically weighted regression: The analysis of spatially varying relationships. London: Wiley.

Ghosh, D., and S.M. Manson. 2008. Robust principal component analysis and geographically weighted regression: Urbanization in the twin cities metropolitan area of Minnesota. Journal of the Urban and Regional Information Systems Association 20(1): 15-25.

Guo, Y. 2012. Urban resilience in post-disaster reconstruction: Towards a resilient development in Sichuan, China. International Journal of Disaster Risk Science 3(1): 45-55.

Hair, J.F. Jr., R.E. Anderson, R.L. Tatham, and W.C. Black. 1998. Multivariate data analysis, 5th edn. Upper Saddle River, New Jersey: Prentice Hall.

Harman, H.H. 1976. Modern factor analysis. Chicago: University of Chicago Press.

Hartigan, J.A., and M.A. Wong. 1979. A K-means clustering algorithm. Journal of the Royal Statistical Society, Series C (Applied Statistics) 28(1): 100-108.

Hastie, T.J., and R.J. Tibshirani. 1990. Generalized additive models. New York: Chapman and Hall. 
Holling, C.S. 1973. Resilience and stability of ecological systems. Annual Review of Ecology and Systematics 4: 1-23.

Holling, C.S. 1996. Engineering resilience versus ecological resilience. In Engineering within Ecological Constraints, ed. P.C. Schulze, 31-44. Washington, DC: National Academy Press.

Jolliffe, I.T. 2010. Principal component analysis, 2nd edn. New York: Springer.

Lam, N.S., M. Reams, K. Li, C. Li, and L.P. Mata. 2015. Measuring community resilience to coastal hazards along the Northern Gulf of Mexico. Natural Hazards Review 17(1). 04015013.

LeSage, J.P. 2004. A family of geographically weighted regression models. In Advances in spatial econometrics: Methodology, tools and applications, ed. L. Anselin, R. Florax, and S.J. Rey, 241-264. Berlin: Springer.

Li, W., C.A. Airriess, A.C.-C. Chen, K.J. Leong, and V. Keith. 2010. Katrina and migration: Evacuation and return by African Americans and Vietnamese Americans in an Eastern New Orleans suburb. The Professional Geographer 62(1): 103-118.

Li, X., N. Lam, Y. Qiang, K. Li, L. Yin, S. Liu, and W. Zheng. 2015a. Measuring county resilience after the 2008 Wenchuan Earthquake. Natural Hazards and Earth System Sciences Discussions 3: 81-122.

Li, X., W. Zheng, D. Wang, L. Yin, and Y. Wang. 2015b. Predicting seismicity trend in southwest of China based on wavelet analysis. International Journal of Wavelets, Multiresolution and Information Processing 13(2). Article no. 1550011: 1-9.

Milligan, G.W., and M.C. Cooper. 1985. An examination of procedures for determining the number of clusters in a data set. Psychometrika 50(2): 159-179.

National Bureau of Statistics of the People's Republic of China. 2001. Tabulation of the 2000 population census of the People's Republic of China. Beijing: China Statistics Press.

Nelson, E., G. Mendoza, J. Regetz, S. Polasky, H. Tallis, D. Cameron, K.M. Chan, G.C. Daily, et al. 2009. Modeling multiple ecosystem services, biodiversity conservation, commodity production, and tradeoffs at landscape scales. Frontiers in Ecology and the Environment 7: 4-11.

Norris, F.H., S.P. Stevens, B. Pfefferbaum, K.F. Wyche, and R.L. Pfefferbaum. 2008. Community resilience as a metaphor, theory, set of capacities, and strategy for disaster readiness. American Journal of Community Psychology 41(1-2): 127-150.

NRC (National Research Council). 2012. Disaster resilience: A national imperative. Washington, DC: The National Academies Press.

Panik, M.J. 2009. Regression modeling: Methods, theory, and computation with SAS. New York: Taylor and Francis Group.

Paton, D., and D.M. Johnston. 2001. Disasters and communities: Vulnerability, resilience and preparedness. Disaster Prevention and Management: An International Journal 10(4): 270-277.

Paton, D., and D.M. Johnston. 2006. Disaster resilience: An integrated approach. Springfield: Charles C. Thomas Publisher.

Paton, D., L. Smith, and J. Violanti. 2000. Disaster response: Risk, vulnerability and resilience. Disaster Prevention and Management 9(3): 173-180.

Peet, R. 1998. Modern geographical thought. Oxford: Blackwell.

Pelling, M. 2003. The vulnerability of cities: Natural disasters and social resilience. London and New York: Earthscan.
Shan, W. 2010. Comparing ethnic minorities and Han Chinese in China: Life satisfaction, economic well being and political attitudes. East Asian Policy 2: 13-22.

Sichuan Provincial Bureau of Statistics. 2003. Sichuan statistical yearbook. Beijing: China Statistics Press.

Sichuan Provincial Bureau of Statistics. 2006. Sichuan statistical yearbook. Beijing: China Statistics Press.

Sichuan Provincial Bureau of Statistics. 2008. Sichuan statistical yearbook. Beijing: China Statistics Press.

Sichuan Provincial Bureau of Statistics. 2009. Sichuan statistical yearbook. Beijing: China Statistics Press.

Sichuan Provincial Bureau of Statistics. 2011. Sichuan statistical yearbook. Beijing: China Statistics Press.

Smith, M. 1998. Social science in question. London: Sage.

The H. John Heinz III Center for Science, Economics, and the Environment. 2000. The Hidden costs of coastal hazards: Implications for risk assessment and mitigation. Washington, DC: Island Press.

Turner, B.L., R.E. Kasperson, P.A. Matson, J.J. McCarthy, R.W. Corell, L. Christensen, N. Eckley, J.X. Kasperson, A. Luers, M.L. Martello, C. Polsky, A. Pulsipher, and A. Schiller. 2003. A framework for vulnerability analysis in sustainability science. Proceedings of the National Academy of Sciences 100(14): 8074-8079.

UNISDR (United Nations International Strategy for Disaster Reduction). 2004. Living with risk: A global review of disaster reduction initiatives. Geneva: UNISDR.

Unwin, D.J. 1996. GIS, spatial analysis and spatial statistics. Progress in Human Geography 20(4): 540-551.

USGS (United States Geological Survey). 2008. Magnitude 7.9: Eastern Sichuan, China. U.S. Geological Survey Earthquake Hazards Program. http://earthquake.usgs.gov/earthquakes/ eqinthenews/2008/us2008ryan/. Accessed 27 May 2016.

Wheeler, D.C., and C.A. Calder. 2007. An assessment of coefficient accuracy in linear regression models with spatially varying coefficients. Journal of Geographical Systems 9(2): 145-166.

Wheeler, D.C., and M. Tiefelsdorf. 2005. Multicollinearity and correlation among local regression coefficients in geographically weighted regression. Journal of Geographical Systems 7(2): 161-187.

Yu, D., N.A. Peterson, and R.J. Reid. 2009. Exploring the impact of non-normality on spatial non-stationarity in geographically weighted regression analyses: Tobacco outlet density in New Jersey. GIScience and Remote Sensing 46(3): 329-346.

Zheng, W., X. Li, N. Lam, X. Wang, S. Liu, X. Yu, Z. Sun, and J. Yao. 2013. Applications of integrated geophysical method in archaeological surveys of the ancient Shu ruins. Journal of Archaeological Science 40(1): 166-175.

Zheng, W., X. Li, J. Xie, L. Yin, and Y. Wang. 2015. Impact of human activities on haze in Beijing based on grey relational analysis. Rendiconti Lincei 26(2): 187-192.

Zheng, W., X. Li, L. Yin, and Y. Wang. 2016. Spatiotemporal heterogeneity of urban air pollution in China based on spatial analysis. Rendiconti Lincei 27(2): 351-356. 